\title{
China's Chang'e-5 Landing Site: An
}

\section{Overview}

Yuqi Qian, Long Xiao*, James W. Head*, Carolyn H. van der Bogert, Harald Hiesinger, Lionel Wilson

- yuqii.qian@gmail.com

Planetary Science Institute, China University of Geosciences, Wuhan, China Departmental of Earth, Environmental, and Planetary Sciences, Brown University, Providence, USA Institut fur Planetologie, Westfälische Wilhelms-Universität Münster, Münster, Germany Lancaster Environment Centre, Lancaster University, Lancaster, UK Institute of Geophysics and Geomatics, China University of Geosciences, Wuhan, China

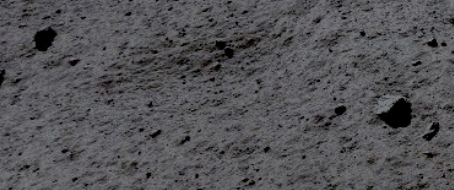




\section{Chang'e-5}

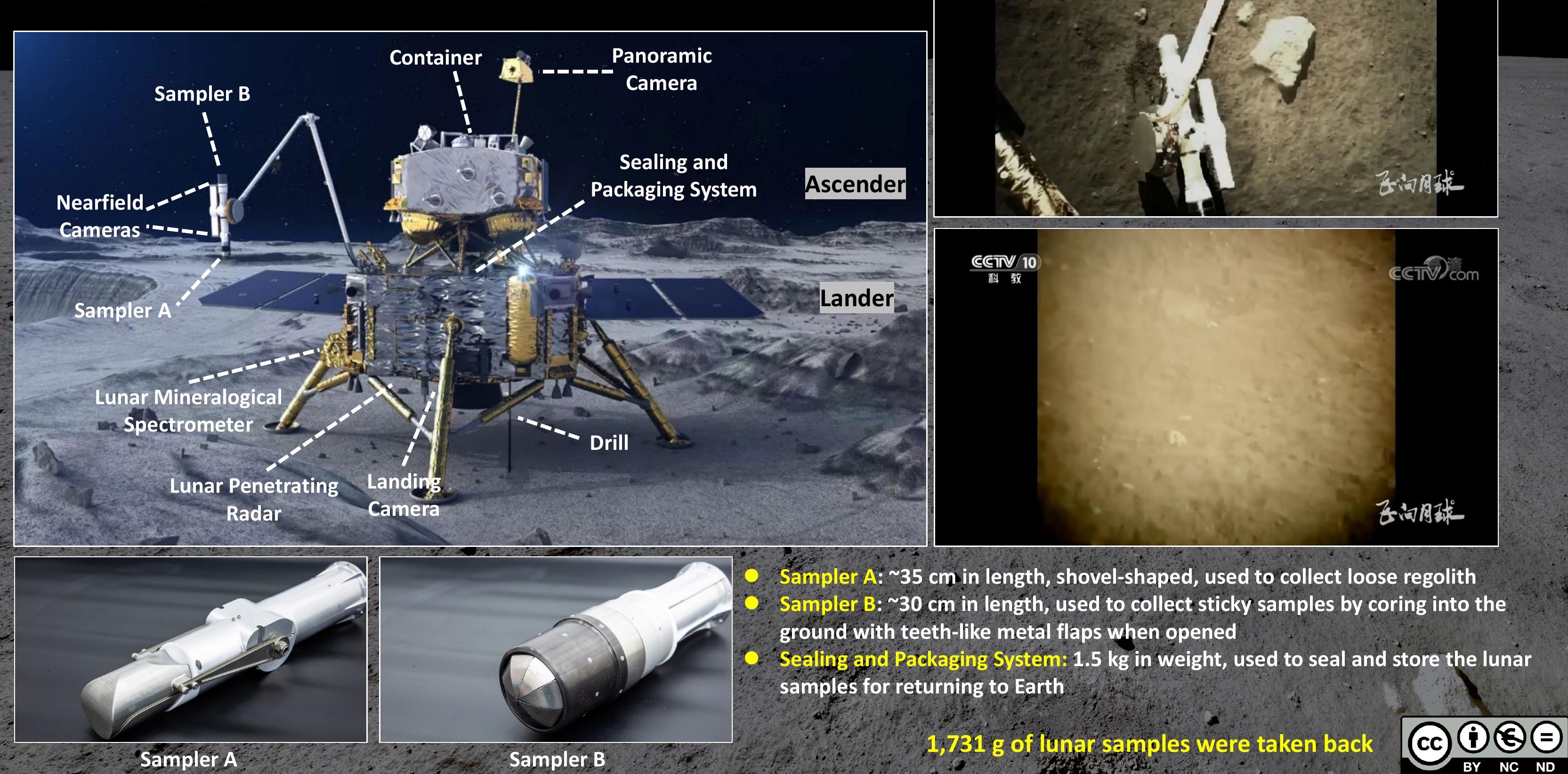




\section{Chang'e-5 Landing Site}

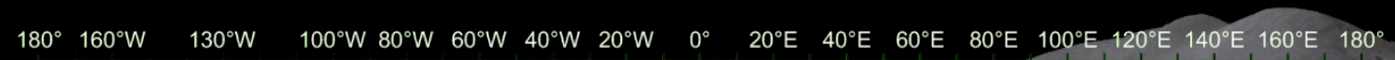

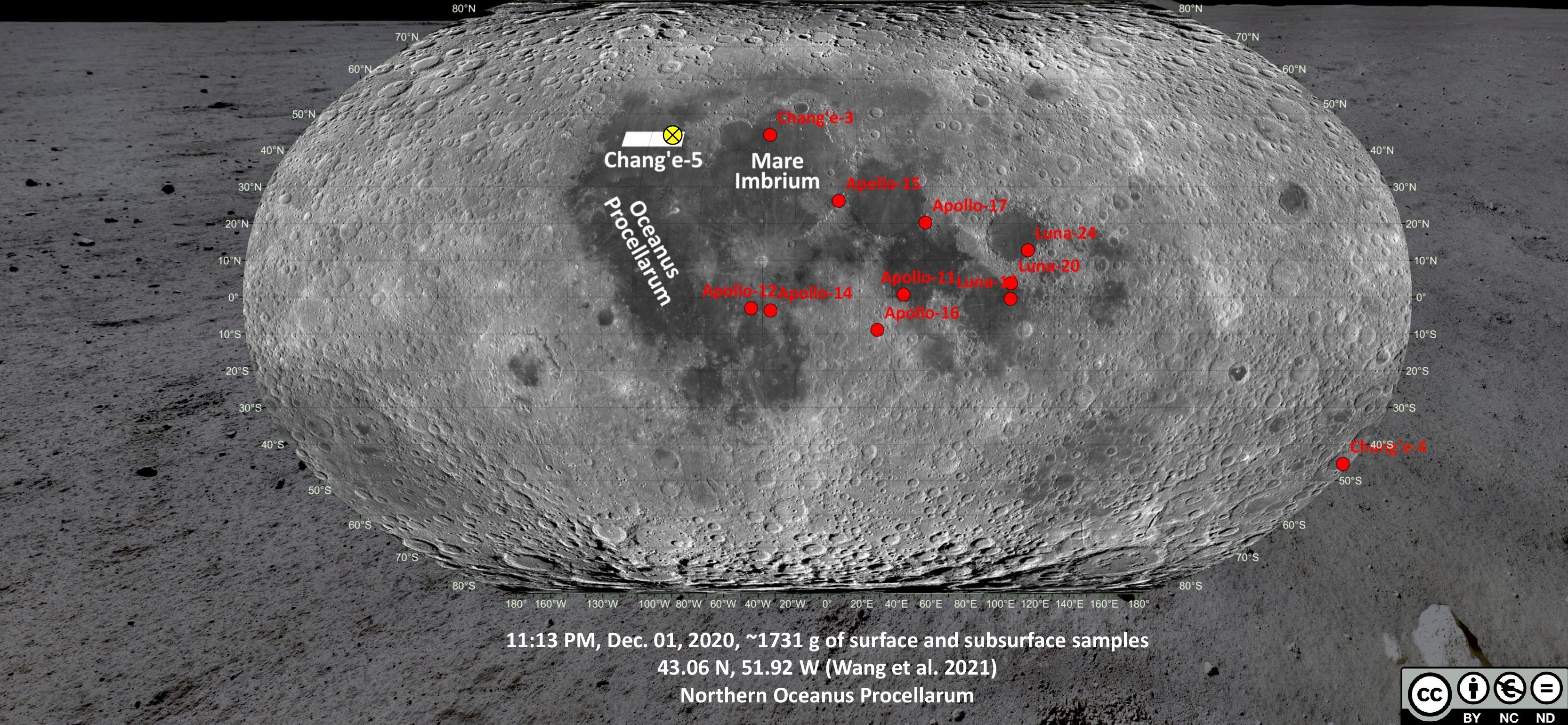




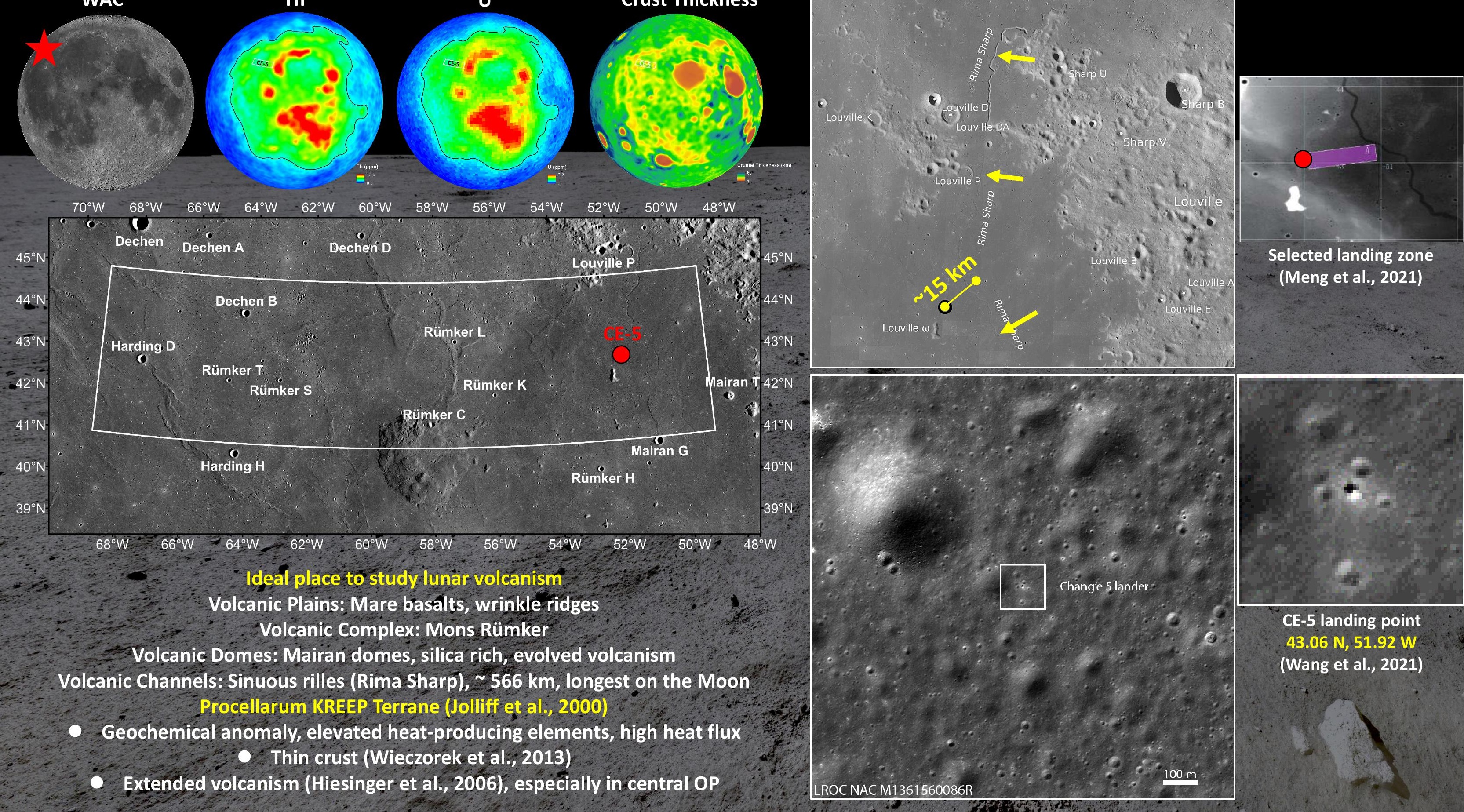




\section{Young Mare Basalts}

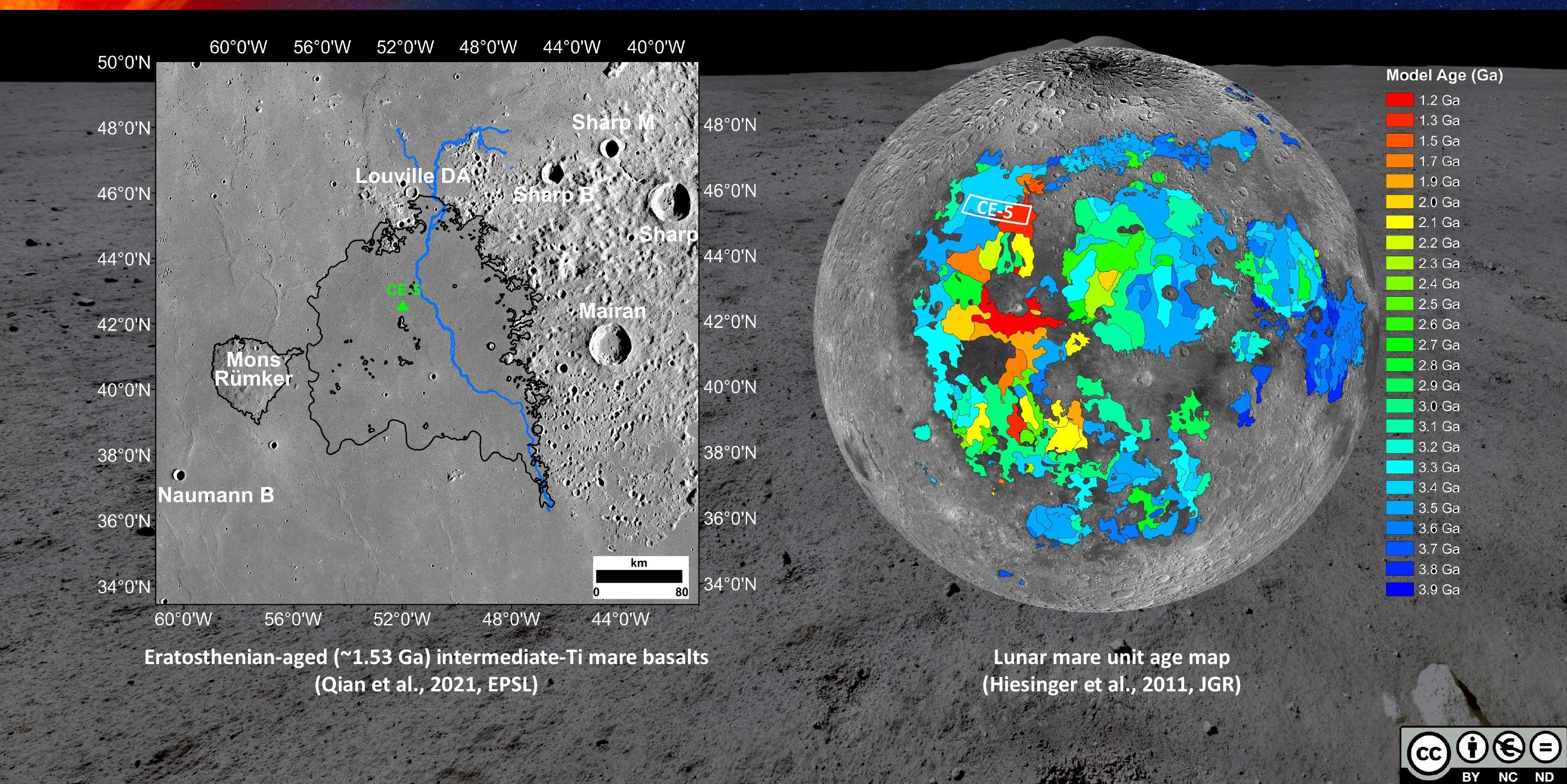




\section{Young Mare Basalts: Composition}

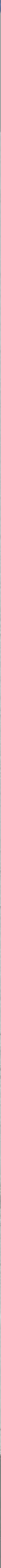




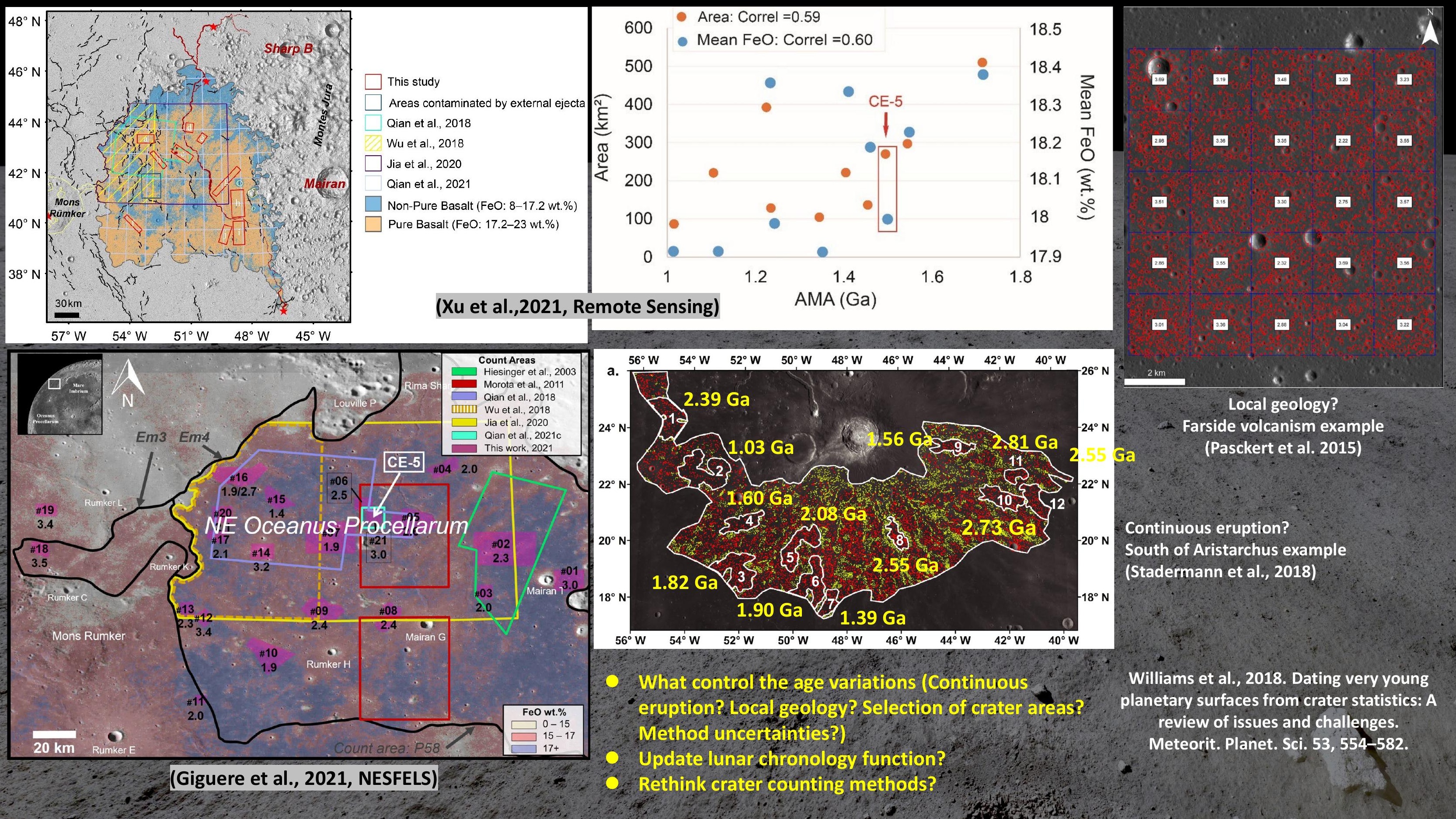




\section{Young Mare Basalts: Origin}

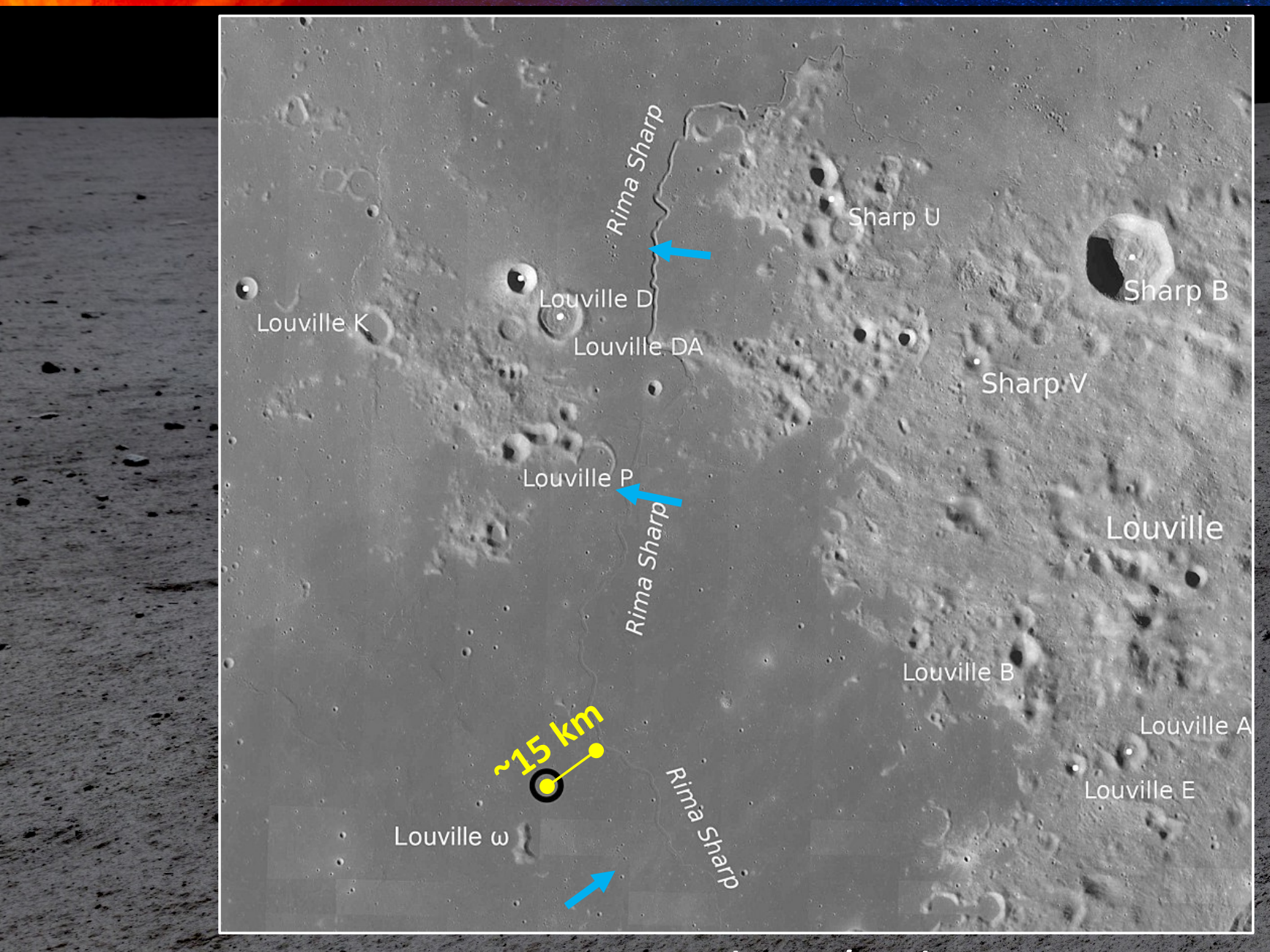

LROC WAC (NASA/ASU)

No observable eruption source vents (i.es, fissures, cones, domes, dikes) for Em4/P58, except for Rima Sharp

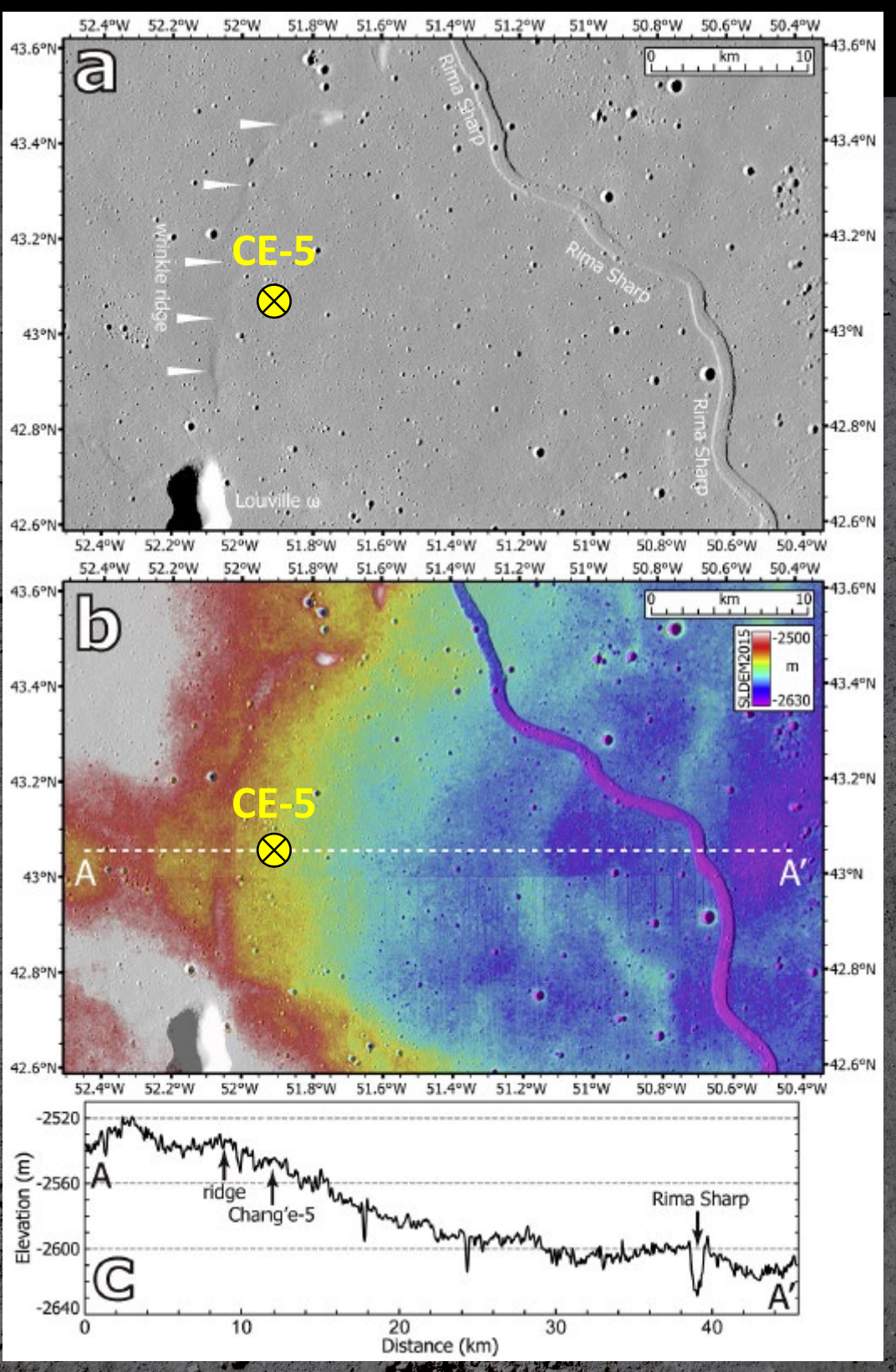

(Qiao et al., 2021,

Icarus) 


\section{In-situ materials: Mare Basalt Origin}

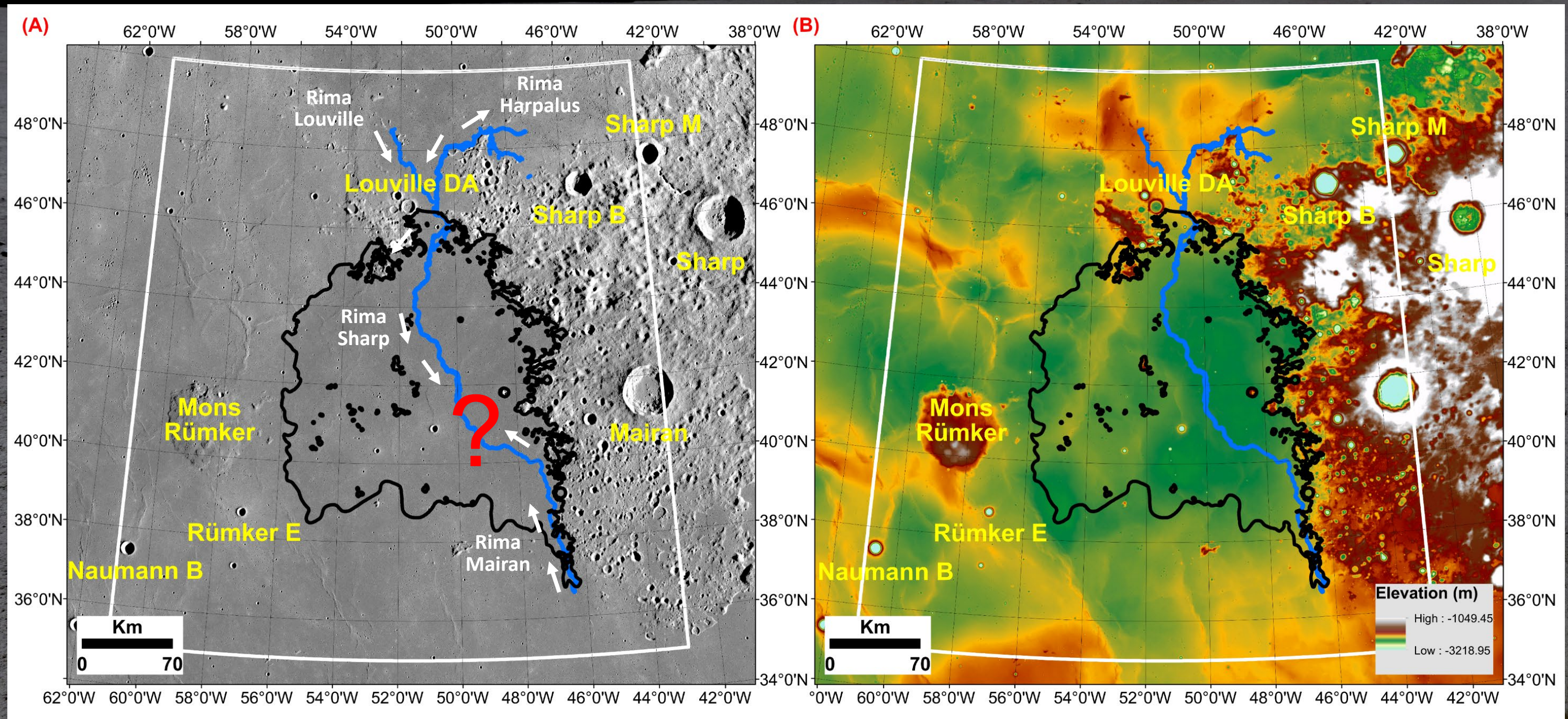


 \\ In-situ materials: Mare Basalt Origin}

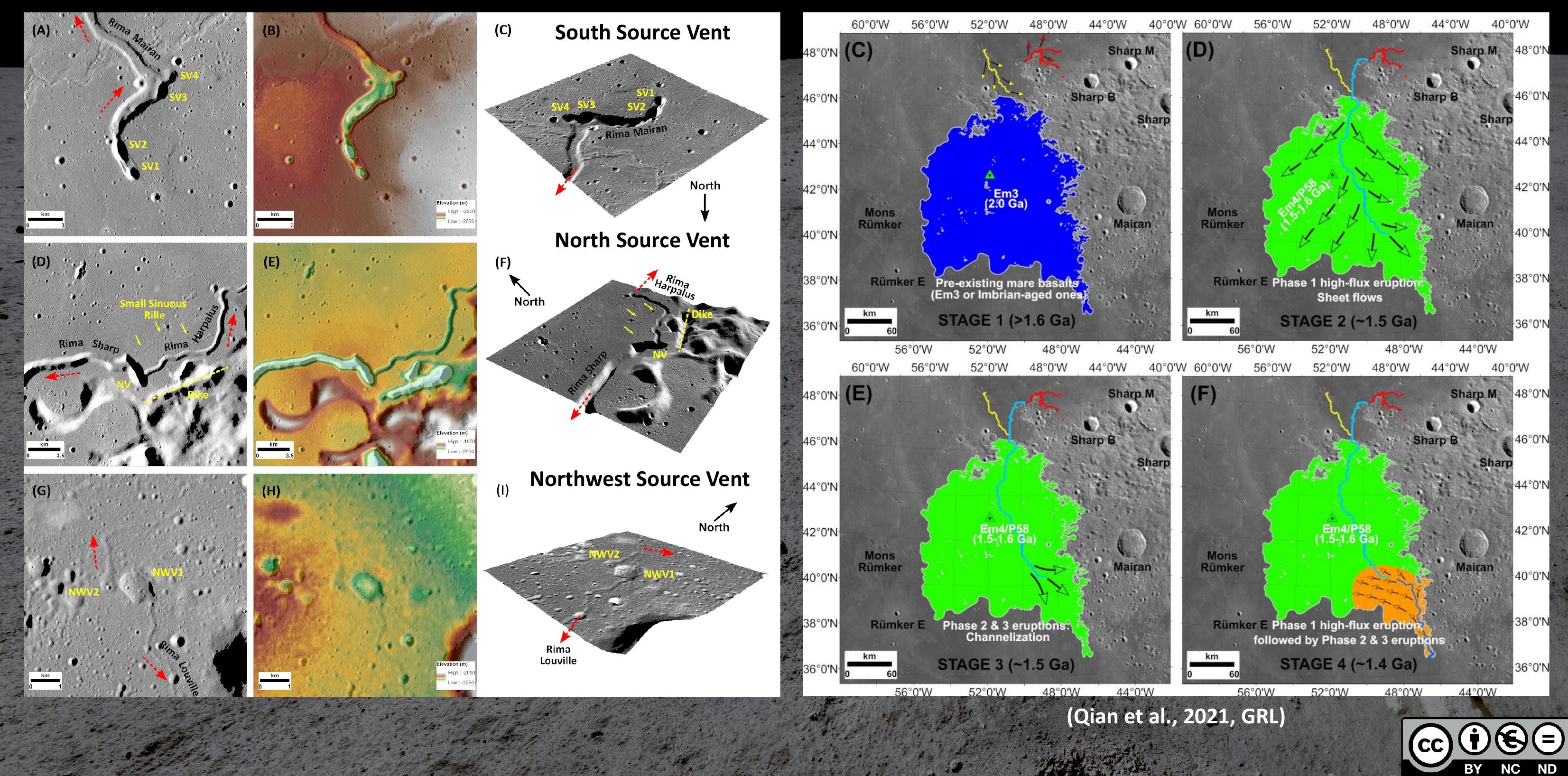




\section{Exotic materials: Impact Ejecta}
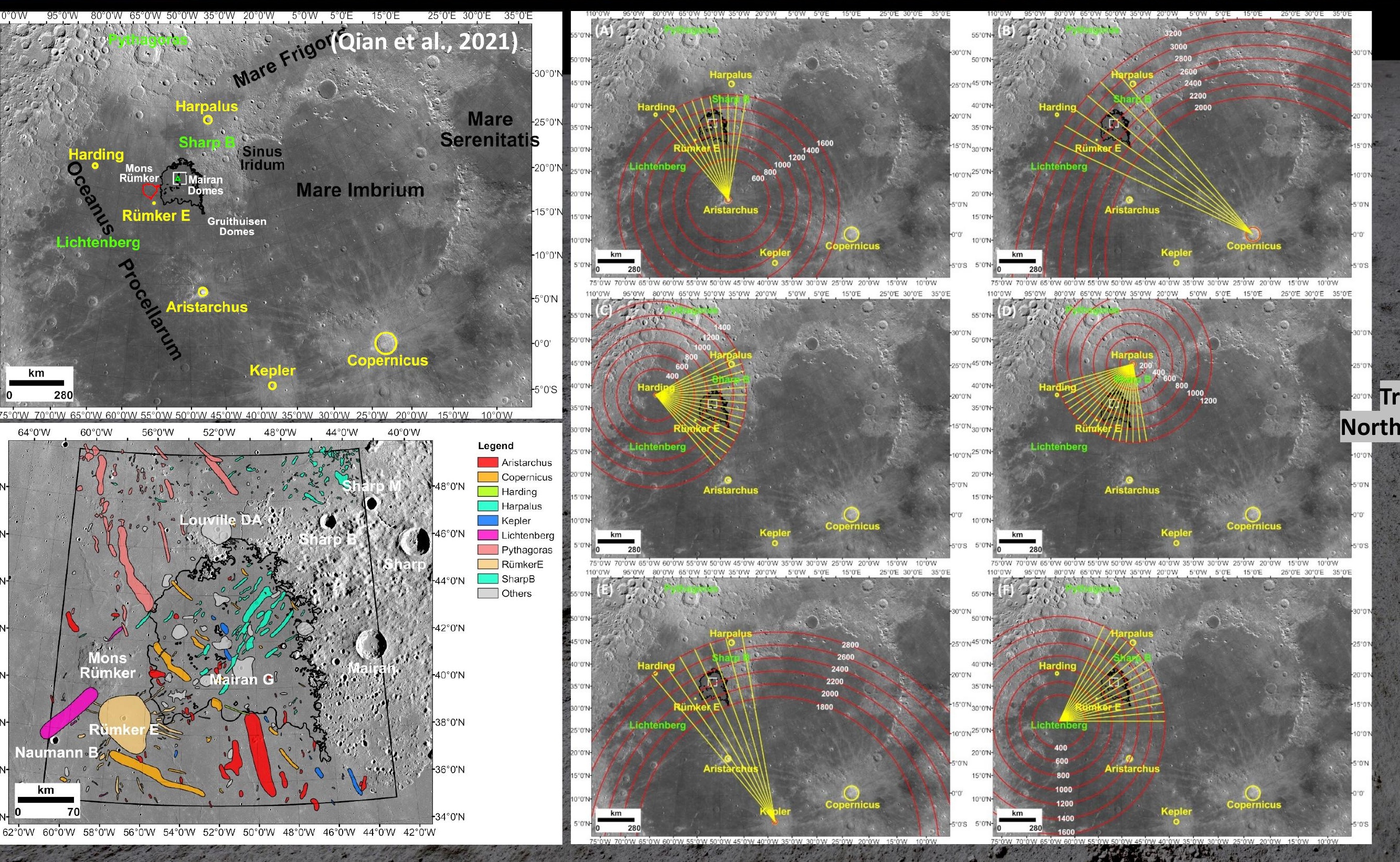

Tracing impact ejecta in Northern Oceanus Procellarum (Qian et al., 2021) 


\section{Conclusion}

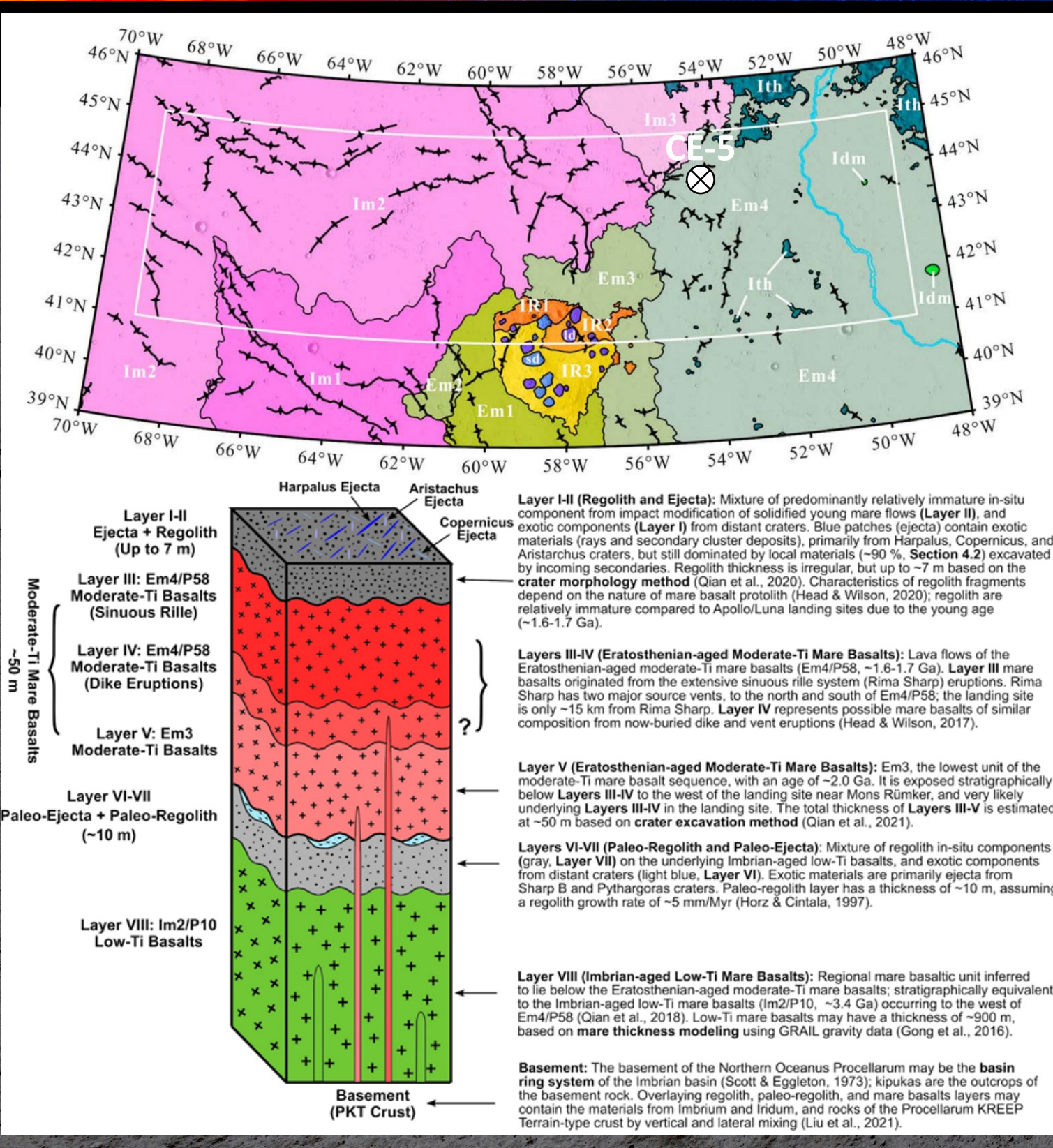

- Chang'e-5 Em4/P58 mare basalt is one of the youngest mare units on the Moon, with ages between $1.2-2.0 \mathrm{Ga}$ dated by different authors, and internal age variations

9. Chang'e-5 Em4/P58 mare basalts are a type of intermediate-Ti basalt with elevated heat-producing elements. Clinopyroxene is the dominant mafic mineral.

- Chang'e-5.Em4/P58 mare basalts may be the products of Rima Sharp eruptions.

- Rima Mairan is younger than Rima Sharp; whose lava buries the southeast portion of Rima Sharp, and enters Rima Sharp, producing inner features and lava ponds within Rima Sharp.

- Exotic materials mainly from Harpalus, Aristarchus, Copernicus craters. Volcanic glass may come from the source vents of Rima Sharp and Rima Mairan.

- Chang'e-5 samples would provide opportunities to calibrate lunar chronology function, with at least two points: 1) local mare basalts, and 2) Harpalus crater.

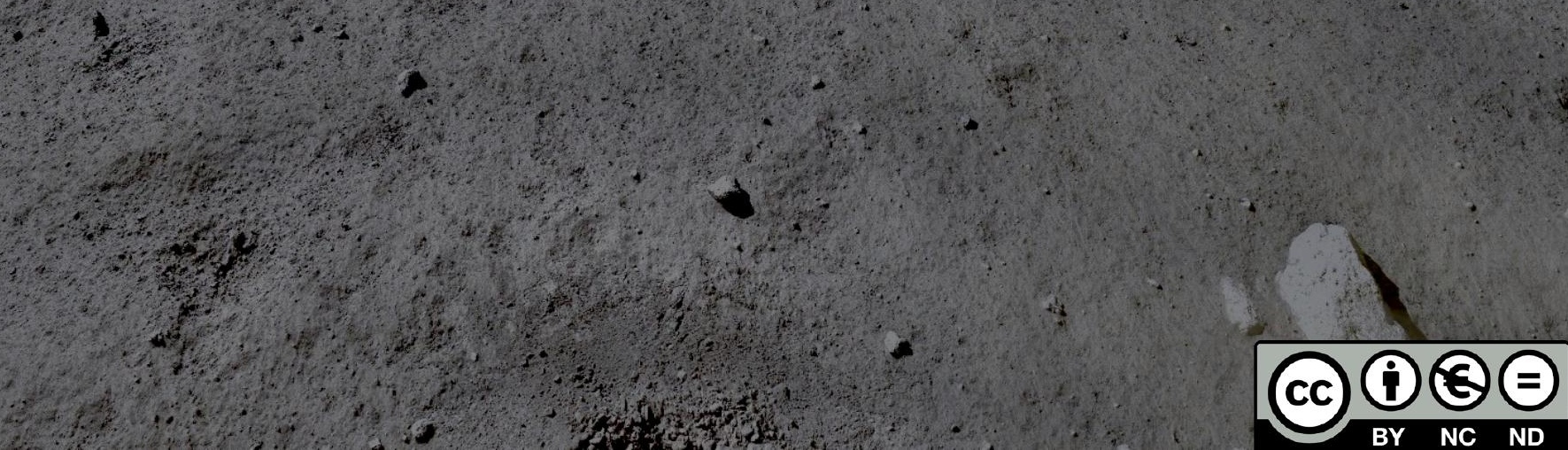

